ACCEPTED MANUSCRIPT

\title{
Capacitance study of a polystyrene nanoparticles capacitor using impedance spectroscopy
}

To cite this article before publication: Bremnen Veliz et al 2019 Nanotechnology in press https://doi.org/10.1088/1361-6528/ab2d58

\section{Manuscript version: Accepted Manuscript}

Accepted Manuscript is "the version of the article accepted for publication including all changes made as a result of the peer review process, and which may also include the addition to the article by IOP Publishing of a header, an article ID, a cover sheet and/or an 'Accepted

Manuscript' watermark, but excluding any other editing, typesetting or other changes made by IOP Publishing and/or its licensors"

This Accepted Manuscript is @ 2019 IOP Publishing Ltd.

During the embargo period (the 12 month period from the publication of the Version of Record of this article), the Accepted Manuscript is fully protected by copyright and cannot be reused or reposted elsewhere.

As the Version of Record of this article is going to be / has been published on a subscription basis, this Accepted Manuscript is available for reuse under a CC BY-NC-ND 3.0 licence after the 12 month embargo period.

After the embargo period, everyone is permitted to use copy and redistribute this article for non-commercial purposes only, provided that they adhere to all the terms of the licence https://creativecommons.org/licences/by-nc-nd/3.0

Although reasonable endeavours have been taken to obtain all necessary permissions from third parties to include their copyrighted content within this article, their full citation and copyright line may not be present in this Accepted Manuscript version. Before using any content from this article, please refer to the Version of Record on IOPscience once published for full citation and copyright details, as permissions will likely be required. All third party content is fully copyright protected, unless specifically stated otherwise in the figure caption in the Version of Record.

View the article online for updates and enhancements. 


\title{
Capacitance study of a polystyrene nanoparticles capacitor using impedance spectroscopy
}

\author{
Bremnen Véliz $^{1,2}$, Albert Orpella ${ }^{2}$ and Sandra Bermejo ${ }^{2}$ \\ ${ }^{1}$ Department of Electronic Engineering, GISCOR Group, Salesian Polytechnic University, Guayaquil, \\ Ecuador \\ ${ }^{2}$ Department of Electronic Engineering, MNT Group, Universitat Politécnica de Catalunya, Barcelona, \\ Spain. \\ E-mail: Sandra.bermejo@upc.edu
}

Received xxxxxx

Accepted for publication $\mathrm{xxxxx \textrm {x }}$

Published xxxxxx

\begin{abstract}
In this study, a metal-insulator-metal capacitor structure is fabricated using polystyrenenanoparticles. Impedance spectrocopy is used to evaluate the performance of this capacitor in which we found out a significant magnitude increment in capacitance and loss tangent compared with an equivalent ideal capacitor with continuous polystyrene layer and same geometry. Capacitance values up to 11.7 and loss tangent values up to 387 (at $0.1 \mathrm{~Hz}$ ) larger than the expected for a continuous polystyrene MIM capacitor are achieved. The capacitor shows a good stable capacitive behavior in the frequency range from $0.1 \mathrm{~Hz}$ to $100 \mathrm{kHz}$ at room temperature, $30^{\circ} \mathrm{C}, 40^{\circ} \mathrm{C}$ and $50^{\circ} \mathrm{C}$ without an effective relaxation process. Nyquist, capacitance, loss tangent and normalized powers curves are analysed by modified randles model. Also, it is observed a slight decrease in the capacitance value at $50^{\circ} \mathrm{C}$ that may be attributed to space charge localized at the nanoparticles interface and that are affected by the temperature changes.
\end{abstract}

Keywords: Polystyrene nanoparticles, metal-insulator-metal structure, impedance spectroscopy, electrospray, space charge polarization.

\section{Introduction}

The current trend to improve energy storage performance is driving to the characterization of different dielectric materials as metal oxides and polymers, as well as, the innovation in different structures at micro and nanoscale. Metal Insulator Metal (MIM) capacitors are used as a secondary power supply [1] in integrated circuits applications and are fabricated using planar and continuous films of high$\mathrm{k}$ dielectrics as insulator layers. Nevertheless, 3D MIM nanostructures such as a nanoscale interdigital aluminum oxide membrane [2] or an nanotubular MIM [3] show an enhanced high density energy and high capacitance as $100 \mu \mathrm{F} / \mathrm{cm}^{2}$. Tree-dimensional nanocapacitors based on nanowires [4] or porous arrays [5] have achieved capacitances of about 10 and 2.5 times greater than for planar capacitor. Moreover, a new and simple fabrication method to selfassembly spherical nanoparticles using electrospray [6] has recently allowed the fabrication of a silica oxide nanoparticles MIM capacitor [7] which exhibited a capacitance 1000 times higher than an ordinary planar silica MIM capacitor.

On the other hand, polymers as dielectric materials are of distinctive interest for owning stable capacitances, low losses and high breakdown strengths; making them attractive in many energy store applications [8] such as film capacitors, gate dielectrics, fuel cells, organic photovoltaics, etc. For instance, the current state of art of polymer dielectric is based on biaxially oriented polypropylene (BOPP) [9] with loss tangent $(\tan \delta)$ of about 0.0002 at $1 \mathrm{khz}$, but modest dielectric permittivity of 2.2 and maximum operating temperature of $85^{\circ} \mathrm{C}$. Recently, oligoaniline, a conductive material, was functionalized inside polystyrene film, and a dielectric constant increase around one order of magnitude was reported [10].

Polystyrene (PS) is a thermoplastic weak-polar polymer [11] constituted by large chain of styrene molecules. It owns 
a dielectric permittivity of about 2.55 and a loss tangent of 0.0002 at glassy-state. Characteristics that make it a good alternative for manufacturing low cost insulators, or capacitors with low losses but low capacitance density. Also, polystyrene nanoparticles layers [12] have been successfully deposited with electrospray as a suitable alternative for giving rise to $3 \mathrm{D}$ colloidal structures as potential devices for nanophotonic applications such as photonic crystals [13] or inverse opals [14] [15].

Polystyrene impedance spectroscopy properties are mainly associated to two mechanisms of polarization [16] dependent on temperature: Dipolar polarization and space charge polarization. Dipolar polarization (also called Debye polarization) [17] is present till $\mathrm{GHz}$ frequencies and it is due to the thermal aligning of groups of proteins known as phenylgroups [18] [19]. Space charge polarization [20] appears at metal-insulator interfaces or grain boundaries, and it is due to the diffusion of charge carries such as electrons, holes and ions.

In this paper, we report the fabrication and study of a new metal-insulator-metal capacitor structure using an array of polystyrene (PS) nanoparticles layers as insulator instead of a continue film of polystyrene. We enclosed the PS nanoparticles using electrospray and standard microelectronic fabrication techniques. Impedance spectroscopy data was measured and modelled at room temperature and at different temperatures below the glass-transition temperature. The improved capacitance and loss tangent were compared with a theoretical polystyrene film capacitor with the same planar area and thickness.

\section{Experimental}

\subsection{Material and device fabrication}

The device consists in two electrodes and some PS nanoparticles in between. The MIM capacitor was fabricated on a glass holder as a substrate, although any other thin or flexible holder could be used, reducing the cost and enhancing the feasibility. First, a photolithography step was performed to pattern a positive photoresist layer as it is shown in Figure 1 a. Then a $355 \mathrm{~nm}$ thick aluminum layer was deposited and then, the sacrificial photoresist layer was removed by a lift-off process thus creating the bottom plate electrode $\left(20.25 \mathrm{~mm}^{2}\right)$ on the glass. A new layer of photoresist was spun-coated and patterned to create two cavities, one cavity for the MIM capacitor and the other for the contact with the bottom electrode.

In order to refill the first cavity with PS-nanoparticles (Figure $1 \mathrm{~b}$ ), the needle tip was placed at $6 \mathrm{~cm}$ from the sample and then a PS colloidal suspension was pumped at $0.3 \mathrm{~mL} / \mathrm{h}$. To form the Taylor cone [21], that is essential to electrospray the nanoparticles, a DC bias of $+5.2 \mathrm{kV}$ was applied at the needle and $-2.1 \mathrm{kV}$ at the bottom electrode. PS-nanoparticles are deposited by electrospray during 5 minutes onto the aluminum layer. The ambient temperature and ambient humidity were monitored at $26^{\circ} \mathrm{C}$ and $70 \%$ respectively.

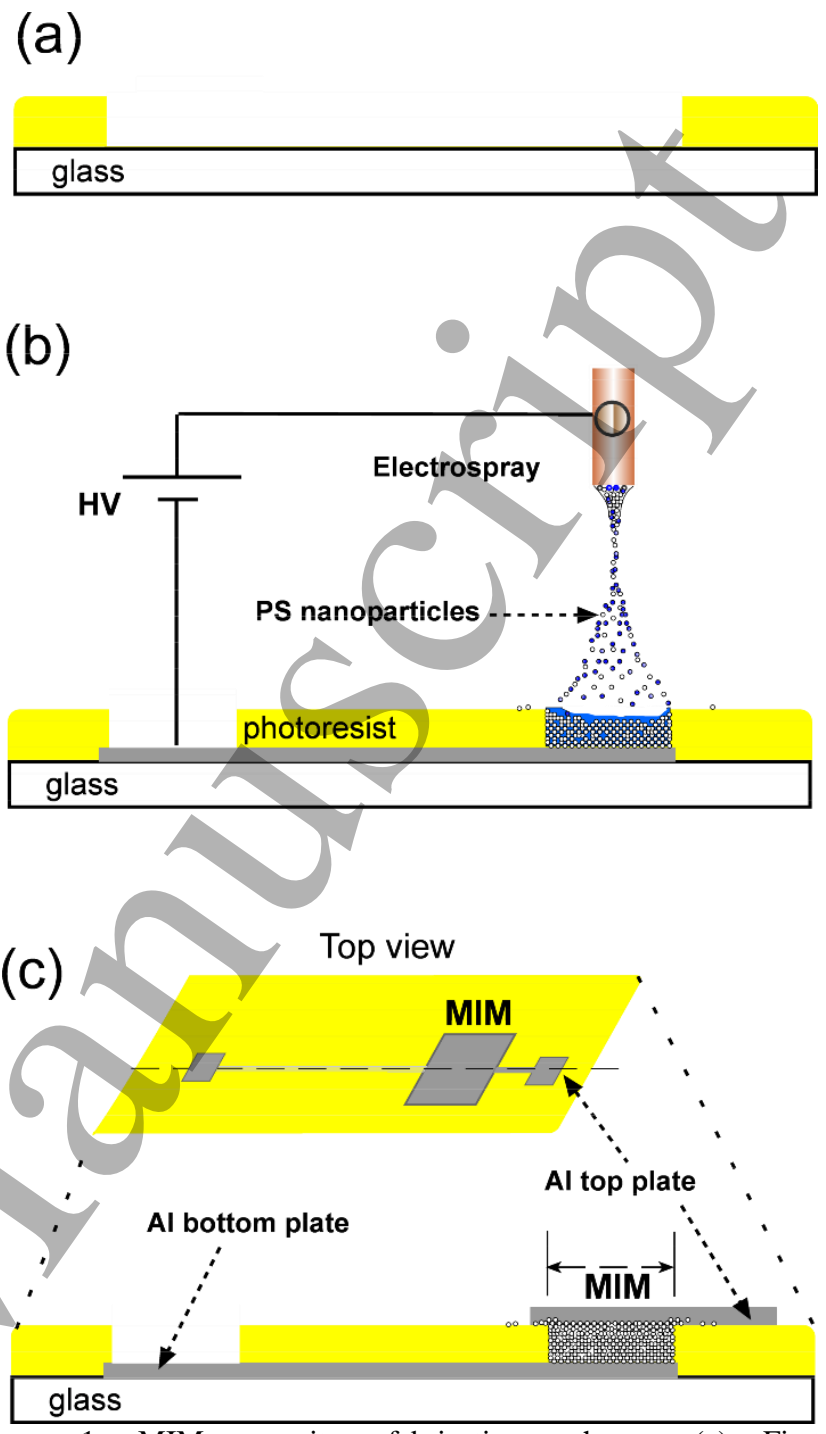

Figure 1. MIM capacitor fabrication scheme: (a) First photolithography step in order to construct the bottom electrode. (b) PS nanoparticles are electrosprayed with a high DC voltage between the needle and the bottom plate. (c) PS nanoparticles were covered by a thermal evaporated aluminium film as the top plate electrode.

The top plate electrode was also an aluminum layer but deposited by thermal evaporation onto the electrosprayed nanoparticles using a shadow mask to close the specific area of the MIM device with aluminum. A sectional top schematic of the device is shown in Figure 1c.

Regarding to the nanoparticles suspension, priory to the electrospray step, we modified the original monodisperse PS nanoparticles water suspension $(295 \mathrm{~nm}$ diameter and solid content weight $5 \%$ ), mixing with propanol with a volume ratio of $6: 4$ respectively.

\subsection{Characterization}

Scanning Electron Microscope (SEM) and Focused Ion Beam (FIB) characterizations were used to obtain the top view and cross-sectional view of the resulting nanoparticle layers. 
Electrical performance of the PS nanoparticle MIM capacitor was measured by impedance spectroscopy over the frequency range from $0.1 \mathrm{~Hz}$ to $100 \mathrm{kHz}$ applying an excitation perturbation voltage amplitude of $500 \mathrm{mV}$ with an impedance analyzer (Hioki IM3590). The impedance measurements were first carried out at room temperature and a temperature sweep was also performed. The temperatures analysis was made using a thermal chuck with a STC200 temperature controller. In order to avoid deformation due to PS dilatation, the temperature range was maintained below the glass-transitiontemperature [22]. Nyquist plot, capacitance values, loss tangent values and normalized power plots are presented.

\subsection{Formulation}

A MIM structure under an alternating electric voltage has an impedance $\mathrm{Z}(\mathrm{f})$ formed by a real and an imaginary component, that can be described as a complex capacitance.

$$
Z(f)=Z^{\prime}+j Z^{\prime \prime}=1 /\left[j 2 \pi f C^{*}\right]
$$

The complex capacitance $C^{*}(\mathrm{f})$ is defined by:

$$
C^{*}(f)=[A / d] \epsilon^{*}=C^{\prime}-j C^{\prime \prime}
$$

Where $A$ is the planar area, $d$ is the thickness and $C^{*}$ is the complex permittivity.

The real capacitance $C^{\prime}$ is related to the energy storage, depends on the frequency and it is proportional to the permittivity $C^{\prime}$. This capacitance can be written as:

$$
C^{\prime}=-Z^{\prime \prime} /\left[2 \pi f|Z|^{2}\right]=[A / d] \epsilon^{\prime}
$$

On the other hand, the loss tangent (or dielectric loss) is a dimensionless parameter defined as follows:

$$
\tan (\delta)=\left|Z^{\prime} / Z^{\prime \prime}\right|
$$

Where $\delta$ is the loss angle. For an ideal capacitor $\tan \delta=0$.

The complex power $\mathrm{S}$ can be defined as:

$$
S=P+j Q \quad(5)
$$

The normalized active power $\mathrm{P}_{\mathrm{N}}$ and the normalized reactive power $\mathrm{Q}_{\mathrm{N}}$ can be written as:

$$
\begin{gathered}
P_{N}=P /|S|=Z^{\prime} /|Z|=\cos (\theta) \\
Q_{N}=Q /|S|=Z^{\prime \prime} /|Z|=\operatorname{sen}(\theta)
\end{gathered}
$$

Where $\theta$ is the phase angle of both the complex power $S$ and the impedance $\mathrm{Z}(\mathrm{f})$.

In addition, a constant phase element [23] impedance can be defined by the equation:

$$
\mathrm{Z}_{\mathrm{CPE}}=1 /\left[\mathrm{Q}_{\mathrm{C}}(\mathrm{j} \omega)^{\alpha}\right]
$$

Where $\alpha$ is a dispersion exponent that ranges between 0 to $1, \mathrm{Q}_{\mathrm{C}}$ is a coefficient that describes the ideal capacitance when $\alpha=1$, and $\omega$ is the angular frequency.

Finally, a Warburg element [24] impedance $Z_{W}$ can be defined by the equation:

$$
\mathrm{Z}_{\mathrm{W}}=\frac{A_{w}}{\sqrt{\omega}}[1-j]=\sqrt{2} A_{w} /[j \omega]^{1 / 2} \quad(9)
$$

Where $A_{W}$ is called Warburg coefficient.

\section{Results and Discussion}

\subsection{SEM/FIB characterization}

Figure 2a shows the SEM image of a top surface view of the PS-nanoparticles MIM capacitor. The orography is rough but regular in general terms, without peaks, holes or breakings. That is due to the mixture of the PS suspension with propanol favors the uniform scattering of the nanoparticles during the electrospray [12].
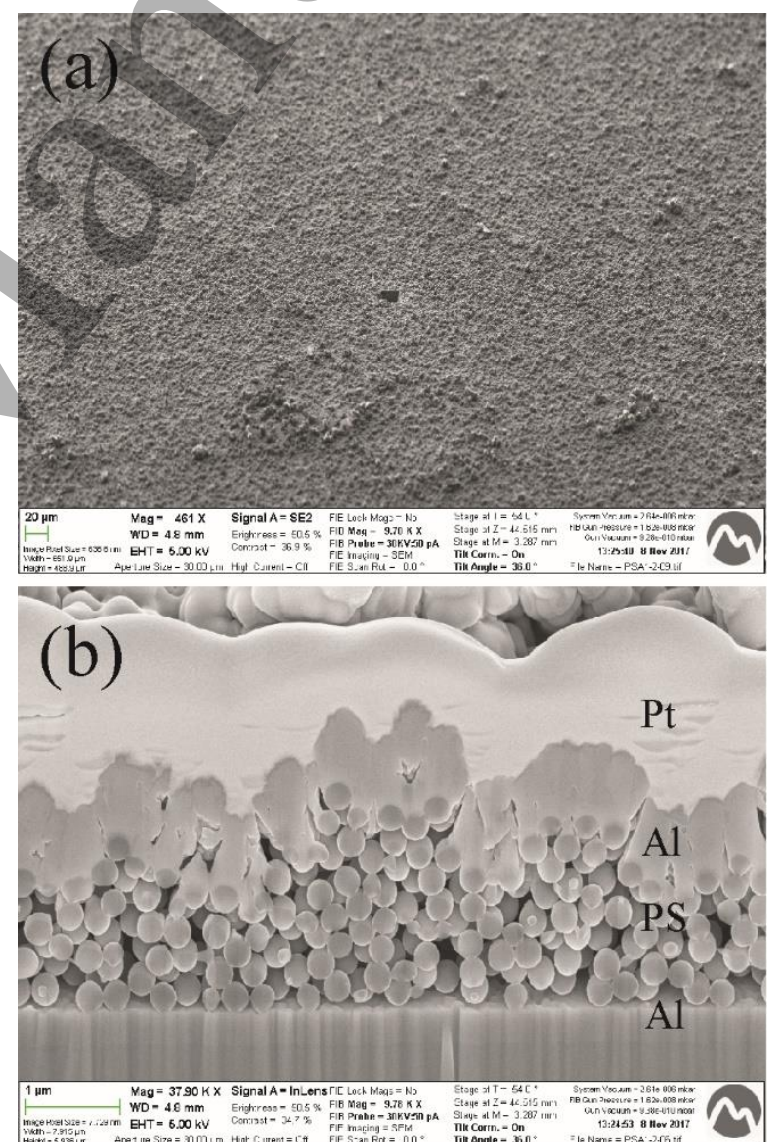

Figure 2. SEM images: Surface top view (a) and cross section view (b) showing PS nanoparticles arranged randomly and sandwiched between two aluminium layers. 
Figure $2 \mathrm{~b}$ shows a cross-section image drilled with FIB where the nanoparticles are sandwiched between the bottom and the top electrodes. A layer of platinum which was deposited with the scanning electron microscope to obtain a good image without electrostatic interference is also observed. As can be seen, the aluminum top electrode has an unevenness but smooth profile. This orography is not easy to control during the fabrication process and it makes difficult to calculate the effective contact area. However, we have estimated an averaged thickness of the PS layer of about 1.75 $\mu \mathrm{m}$.

\subsection{Impedance spectroscopy characterization at room temperature.}

Figure 3a shows the Nyquist plot of the MIM capacitor at a room temperature of $21.5^{\circ} \mathrm{C}$. High impedance values demonstrate a good insulation role of PS nanoparticles. The measured impedance data has been fitted with a modified randles spectral model which equivalent circuit consisted of four sub-circuits, that is shown in Figure 3c. The extracted circuit element values are shown in Table 1, where $\mathrm{Q}_{\mathrm{C} 1}, \mathrm{Q}_{\mathrm{C} 2}$, $\mathrm{Q}_{\mathrm{C} 3}, \mathrm{Q}_{\mathrm{C} 4}$ are the coefficients of the four constant phase elements which represent no uniform accumulation of charges. $\mathrm{Z}_{\mathrm{W} 1}$ corresponds to a Warburg element that is related to a diffusion process; and $\mathrm{R}_{2}, \mathrm{R}_{3}$ and $\mathrm{R}_{4}$ are shunt resistors.

We propose this model continuing with a previous work, where silicon oxide nanoparticles MIM capacitors [7] were analyzed using an equivalent circuit consisting of three subcircuits that models the two contacts (top and bottom) and the $\mathrm{SiO}_{2}$ nanoparticles. Since the top contact/ of the PS nanoparticles MIM is much rougher than $\mathrm{SiO}_{2}$ nanoparticles MIM, the nanoparticles and the aluminum are contacted at different heights with respect to the bottom contact, which may suggest more than one resonance frequency. Therefore, we assume that the top contact can be represented by two subcircuits in series. In addition, the bottom $\mathrm{Al} / \mathrm{PS}$ contact is represented by a sub-circuit $\left(\mathrm{Q}_{\mathrm{C} 2}\right.$ and $\left.\mathrm{R}_{2}\right)$.

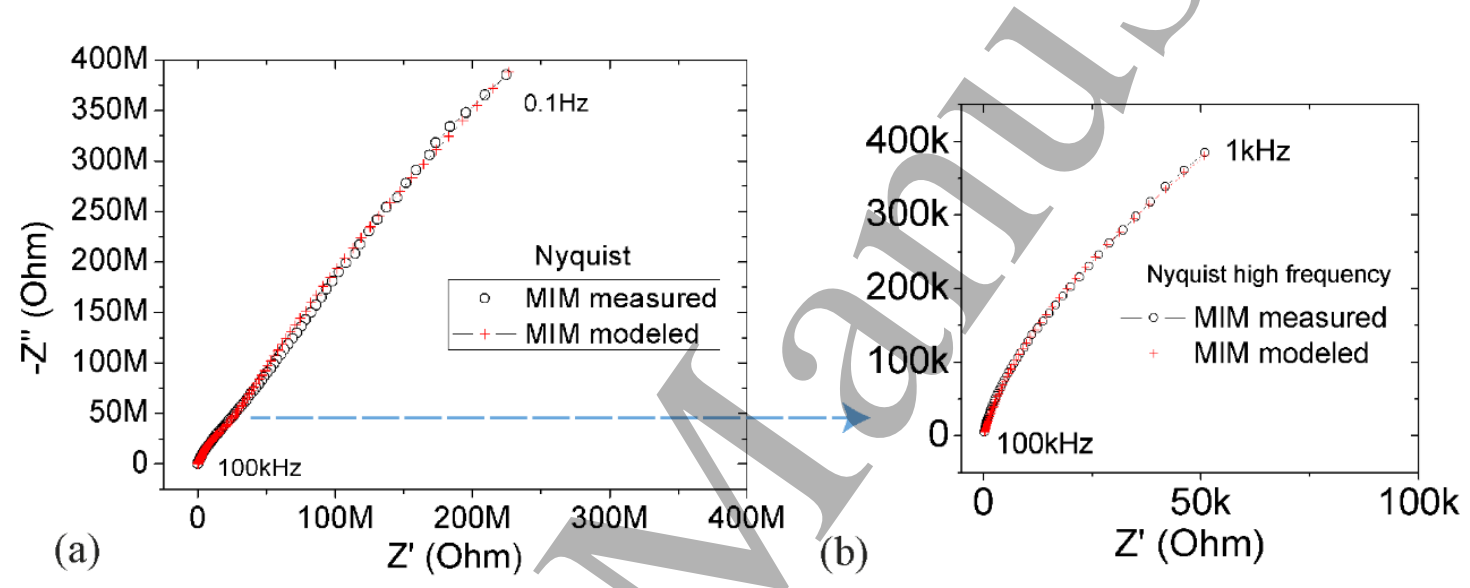

(c)

Figure 3. Nyquist plots (symbols: -o- data measured, -+- data fitted) at 500mVac and at room temperature: (a) Range frequency from $0.1 \mathrm{~Hz}$ to $100 \mathrm{kHz}$, (b) Range frequency from $1 \mathrm{kHz}$ to $100 \mathrm{kHz}$. (c) Equivalent circuit used to fit the impedance data, where parallel sub-circuits represent the top PS/Al contact, the bottom PS/Al contact and the PS nanoparticles. 
Table 1. Fitting parameter for the equivalent circuit of the PS nanoparticles MIM capacitor, $s=j \omega$

\begin{tabular}{llllllllllllll}
\hline & $\mathbf{Q}_{\mathrm{C} 1}$ & $\boldsymbol{\alpha}_{1}$ & $\mathbf{A}_{\mathrm{W} 1}$ & $\mathbf{Q}_{\mathrm{C} 2}$ & $\boldsymbol{\alpha}_{2}$ & $\mathbf{R}_{2}$ & $\mathbf{Q}_{\mathrm{C} 3}$ & $\boldsymbol{\alpha}_{3}$ & $\mathbf{R}_{3}$ & $\mathbf{Q}_{\mathrm{c} 4}$ & $\boldsymbol{\alpha}_{4}$ & $\mathbf{R}_{4}$ & Cresist \\
Unit & $\mathrm{nFs}^{\alpha-1}$ & & $\mathrm{M} \Omega \mathrm{s}^{1 / 2}$ & $\mathrm{nFs}^{\alpha-1}$ & & $\mathrm{M} \Omega$ & $\mathrm{nFs}^{\alpha-1}$ & & $\mathrm{M} \Omega$ & $\mathrm{nFs}^{\alpha-1}$ & & $\mathrm{M} \Omega$ & $\mathrm{pF}$ \\
\hline Value & 1.55 & 0.97 & 390 & 2.2 & 0.93 & 22 & 1.4 & 0.99 & 1.5 & 2.5 & 1 & 0.10 & 33 \\
\hline
\end{tabular}
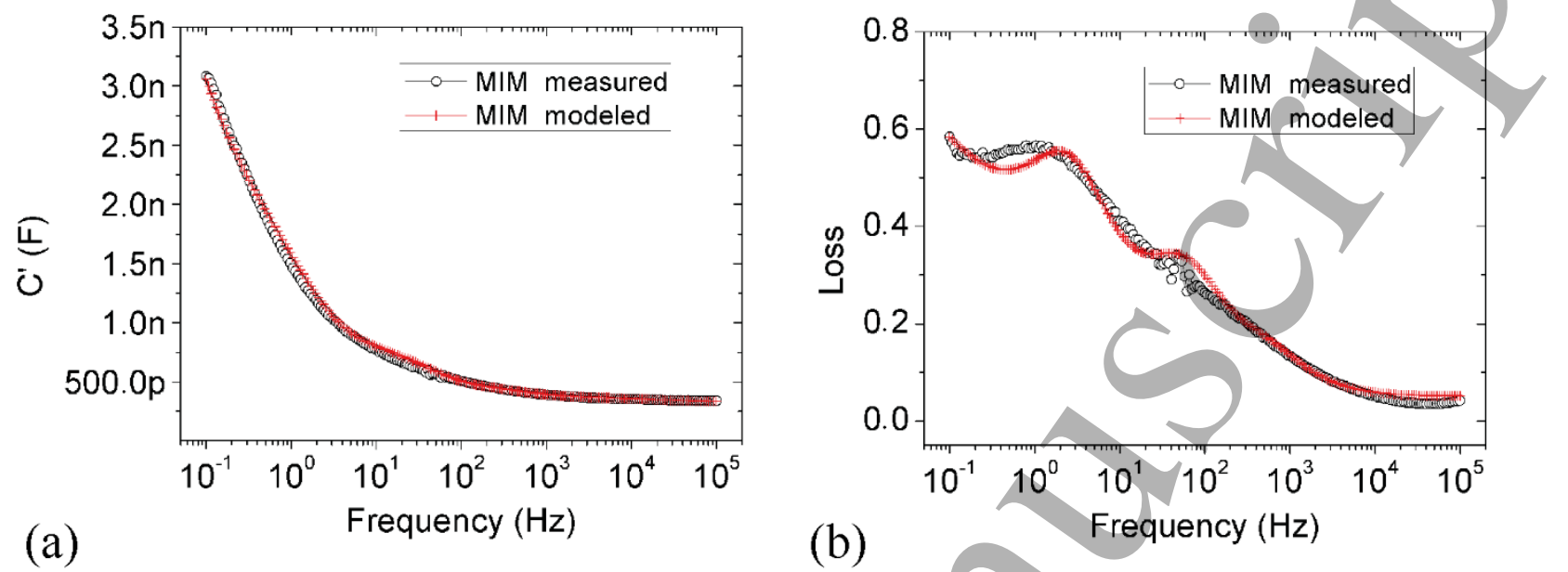

Figure 4. Experimental and modelled data (symbols: -o- and -+-) of capacitance (a) and loss tangent (b) at room temperature from $0.1 \mathrm{~Hz}$ to $100 \mathrm{kH}$

The four sub-circuits are overlapped in frequency, the resonant frequency of each sub-circuit is in the frequency range from $0.2 \mathrm{~Hz}$ to $673 \mathrm{~Hz}$. These frequencies are so close that make it hard to identify the physical origin of each resonance process. Nevertheless, it seems that the sub-circuit that contains the Warburg impedance represents the nanoparticles because the diffusion is developed through the layers of nanoparticles and $\mathrm{Q}_{\mathrm{C} 1}$ is the result of complex mobile charges interacting with polystyrene and its free spaces, while the sub-circuits without Warburg are the MIM contacts. The top contact, where there is more contact area, is represented by the two sub-circuits whose resistances are the smallest. The second sub-circuit whose $\mathrm{R}_{2}$ shunt resistance is the lager than $\mathrm{R}_{3}$ or $\mathrm{R}_{4}$ would be the bottom contact.

There is a capacitance due to photoresist localized in lateral area next to the MIM area. In order to consider the effect of photoresist, a separated Al/photoresist/Al MIM was fabricated and its capacitance was measured. Consequently, the photoresist in-between parallel plates capacitance in our polystyrene nanoparticle $\mathrm{MIM}$ is estimated as $33 \mathrm{pF}\left(\mathrm{C}_{\text {resist }}\right)$.

As a result of the overlapping of the four resonant processes, the Nyquist plot exhibits a straight line (Figure 3a). We can say that the first sub-circuit dominates the region of lowest frequencies, the second one dominates low and intermediate regions, the third one dominates an intermediate region, while the fourth sub-circuit is prevalent for the highest frequencies. Moreover, the Warburg behavior is clearly predominant over the shunt resistors, which can be quantified by means of the ratio $A_{W_{1}} /\left(R_{2}+R_{3}+R_{4}\right) \approx 16.53$ from Table 1 . We found out that $A_{W}$ has greater effect at low frequencies till around $2 \mathrm{kHz}$. At high frequencies $(>1 \mathrm{kHz})$, the model also fits very well due to the other three sub-circuits. The three subcircuits correspond to three depressed semicircles in the Nyquist plot, but due to the high Warburg coefficient, these semicircles are not observed in Figure $3 b$.

The parameters $\mathrm{Q}_{\mathrm{C}}$ of the constant phase elements contribute to the capacitance C' that varies with frequency, whose maximum value is $3.1 \mathrm{nF}$ (at $0.1 \mathrm{~Hz}$ ) for the MIM. In order to investigate the frequency dispersion for the MIM including its modelling, capacitance $C^{\prime}$ and loss tangent curves defined by equations 3 and 4, are shown in Figure 4.

In Figure 4a, a significant decay is found in the capacitance in the range from $0.1 \mathrm{~Hz}$ to $100 \mathrm{~Hz}$. This dispersion could be for a phenomena of formation of charge polarization on the nanoparticles surfaces. On the contrary, more stable frequency response is observed at frequencies from $100 \mathrm{~Hz}$ to $100 \mathrm{kHz}$. The whole capacitance of the PS layers with nanospheres and voids would be expected to be lower than a polystyrene film MIM capacitor of the same planar geometry. However, the measured capacitance is always higher, so the rate between the measured and theoretical capacitance is 11.7 at $0.1 \mathrm{~Hz}$ whereas that at $1 \mathrm{kHz}$ the rate is 1.5 .

Table 2. Comparison of capacitance and loss tangent: an expected theoretical PS film MIM capacitor with our novel PS nanoparticles MIM capacitor at room temperature.

\begin{tabular}{ccc}
\hline & C & Tan $\boldsymbol{\delta}$ \\
\hline Theoretical PS film MIM & $0.26 \mathrm{nF}(1 \mathrm{kHz})$ & $15 \times 10^{-4}(1 \mathrm{kHz})$ \\
capacitor & & \\
\hline Measured PS nanoparticles & $3.10 \mathrm{nF}(0.1 \mathrm{~Hz})$ & $0.58(0.1 \mathrm{~Hz})$ \\
MIM capacitor & $0.39 \mathrm{nF}(1 \mathrm{kHz})$ & $0.13(1 \mathrm{kHz})$ \\
\hline
\end{tabular}

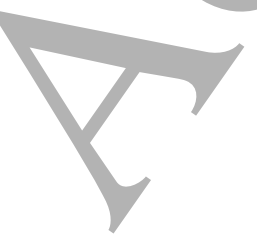




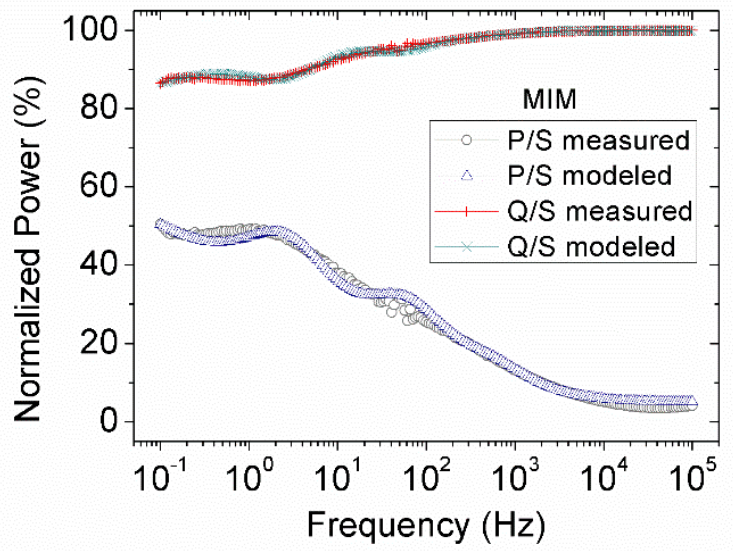

Figure 5. Experimental and modelled normalized powers where $\mathrm{Q} /|\mathrm{S}|>\mathrm{P} /|\mathrm{S}|:(-\circ-) \mathrm{P} / \mathrm{S}$ is the measured normalized active power and $(-\Delta-) \mathrm{Q} / \mathrm{S}$ is the measured normalized reactive power. $(-\mid-) \mathrm{P} / \mathrm{S}$ is the modeled active power and $\left(-\mathrm{X}_{-}-\right) \mathrm{Q} / \mathrm{S}$ is the modeled reactive power.

Table 2 shows the capacitance of an expected continuous PS film MIM capacitor compared to values of the PS nanoparticles MIM structure. We have calculated the theoretical capacitance value taking a planar area of $20.25 \mathrm{~mm}^{2}$, an average dielectric constant of 2.55 and an average thickness of $1.75 \mu \mathrm{m}$.

The increase in capacitance means a higher presence of charges in the nanoparticles MIM capacitor than in a conventional film MIM capacitor. We have already noticed a singular increase in capacitance with the silica nanoparticles [7] [25] in part associated to the humidity and its ions contribution, such as free hydrogens and hydroxyls groups moving on the silica surface. These charges arise from remnants of water molecules deposited by the electrospray phase. Therefore, we interpret that space charge polarization [20] is due to the free ions at the PS nanoparticles boundaries affecting positively to increase the capacitance specially at low frequency range. Nevertheless, as the frequency increases, ions cannot follow the electric field, the space charge polarization begins to disappear, and the weak dipolar polarization, the electronic and atomic polarization [26] that occur in the PS interior, remain.

As it can be seen in Figure 4b, loss tangent decreases with the frequency which is not usual in polystyrene film capacitors [27] [28]. Furthermore, loss values range from 0.58 to 0.035 meaning a stronger increment up to 387 times compared to the ordinary value found in the literature [11], as it is shown in Table 2. We believe that the boundaries between nanoparticles produce different conduction paths that are very resistive, causing more loss of energy than in a PS film MIM capacitor.

Normalized powers as a function of the frequency are observed in Figure 5. They have a perfect capacitive behaviour because reactive power is always higher than active power $(\mathrm{Q} /|\mathrm{S}|>\mathrm{P} /|\mathrm{S}|)$ since there is not an effective relaxation process associated to a space charge relaxation. However, a relaxation point (where $\mathrm{Q} /|\mathrm{S}|=\mathrm{P} /|\mathrm{S}|$ ) could appear below the range of investigation. At high frequencies, the normalized powers are more separated, which means a better capacitive performance because the charges are stored with low loss energy.

Obviously, the cheminal nature of nanoparticle surface tends to allow the moving and orientation of surrounding ions and electrons that governing the electrical behavour. For instance, we noticed non stable capacitive behavours with silica nanoparticles MIMs reported in our former work. Paradoxically, capacities density of up to $2.63 \mu \mathrm{F} / \mathrm{cm}^{2}$ were found at $0.1 \mathrm{~Hz}$ with silica nanoparticles. Meanwhile, capacitive density for the MIM of this work was $15.3 \mathrm{nF} / \mathrm{cm}^{2}$. In spite of everything, the capacitance gain factor of this MIM is in the same order than nanocapacitors based on nanowires [4] (10 times greather than for planar capacitor).

\subsection{Impedance spectroscopy at different temperatures}

Temperature measurements have been performed at $30^{\circ} \mathrm{C}$, $40^{\circ} \mathrm{C}$ and $50^{\circ} \mathrm{C}$. Table 3 shows the fitted parameters with the increase in temperature using the same circuit defined in Figure 3c.

As it can be seen in Figure 6a, a lineal behavior is kept at low frequencies exhibiting some noise as a consequence of the heating. In the range from $1 \mathrm{kHz}$ to $100 \mathrm{kHz}$ shown in Figure $6 \mathrm{~b}$, it is revealed that the curve tilts more toward the vertical axis as the temperature increases. This happen because $Z$ ' decreases and hence, the loss tangent also decreases at that frequencies range. For instance, the loss tangent is 0.13 at room temperature and at $1 \mathrm{kHz}$ as it can be observed in Table 2 , while at $50^{\circ} \mathrm{C}(1 \mathrm{kHz})$, the loss tangent changes to 0.058 . The circuit model indicates that the reason of the Nyquist inclination is mainly due to the increase of the shunt resistor $\mathrm{R}_{4}$. We assumed that this parameter belongs to the top contact. All shunt resistors and the Warburg coefficient increase in value as the temperature increases. However, the increase in shunt resistances in proportion to the Warburg is a little higher, so the merit factor $A_{w 1} /\left(R_{2}+R_{3}+R_{4}\right)$ always decreases with the temperature: 17.11 for $30^{\circ} \mathrm{C}, 15.76$ for $40^{\circ} \mathrm{C}$ and 12.3 for $50^{\circ} \mathrm{C}$. In our opinion, the charge concentration is reduced in the interface contacts due to the increase in temperature that produces a decrease in humidity, and therefore, an increase in the shunt resistors. In addition, the temperature increase produces also an increase in the Warburg impedance. We believe that the Warburg coefficient is following a similar behavior to the classic ions diffusion [29] in a solution because the coefficient has a direct relation with temperature.

On the other hand, the coefficients $\mathrm{Q}_{\mathrm{C} 1}, \mathrm{Q}_{\mathrm{C} 2}, \mathrm{Q}_{\mathrm{C} 3}$ and $\mathrm{Q}_{\mathrm{C} 4}$ showed a little decrease in their values as the temperature increases.

Moreover, a slight decrease in the capacitance associated with the merit factor can be predicted by looking at Figure 7, where we have plotted the ratio between the measured capacitance and the theoretical capacitance at $0.1 \mathrm{~Hz}$ and $1 \mathrm{Khz}$ as a function of our merit factor. Similarly, since the space charges due to the moisture are evaporated, they can no longer contribute with more accumulation of charges. Consequently, the capacitance drops with temperature. 


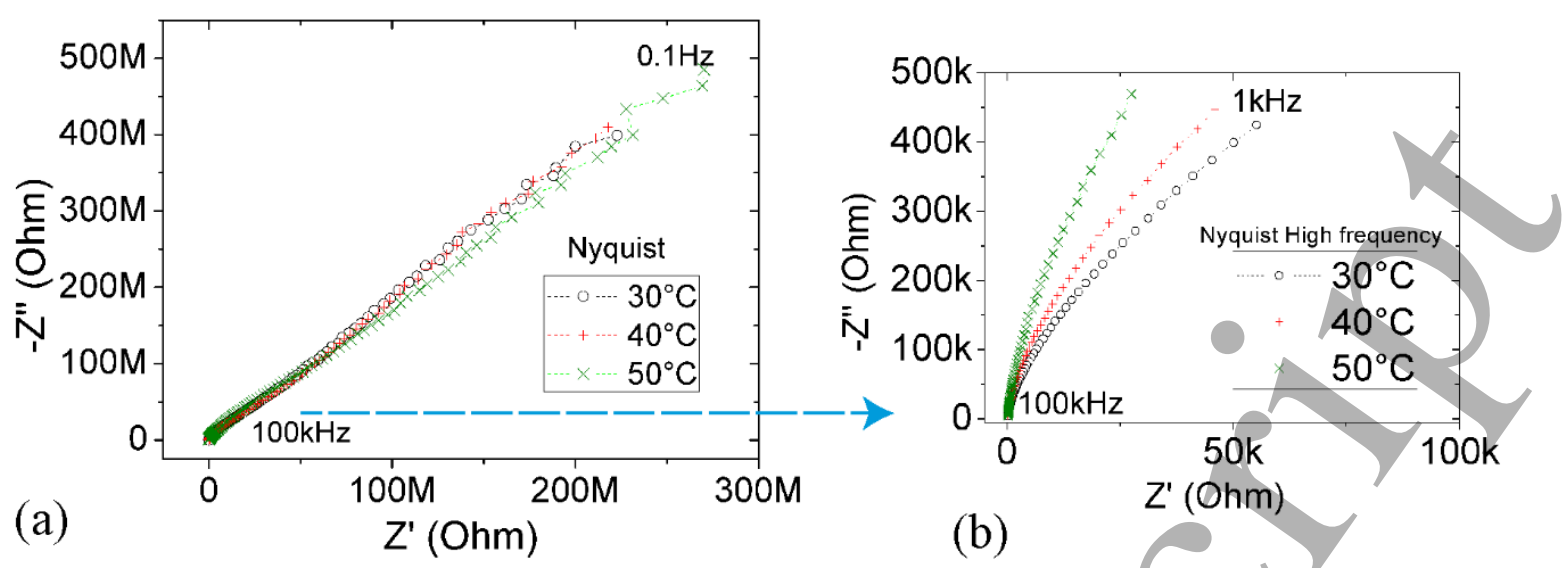

Figure 6. Nyquist plots at $30^{\circ} \mathrm{C}, 40^{\circ} \mathrm{C}$ and $50^{\circ} \mathrm{C}$ : (a) From $0.1 \mathrm{~Hz}$ to $100 \mathrm{kHz}$, exhibiting a lineal behaviour with some noise at low frequency. (b) Exhibiting a reduction $Z$ ' in the frequency range from $1 \mathrm{kHz}$ to $100 \mathrm{kHz}$.

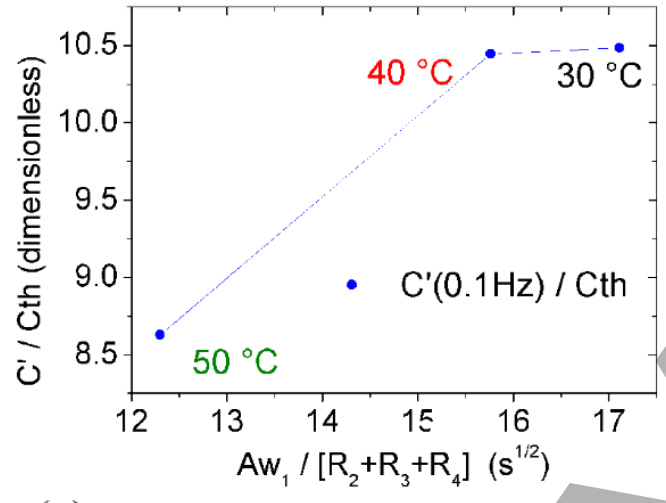

(a)

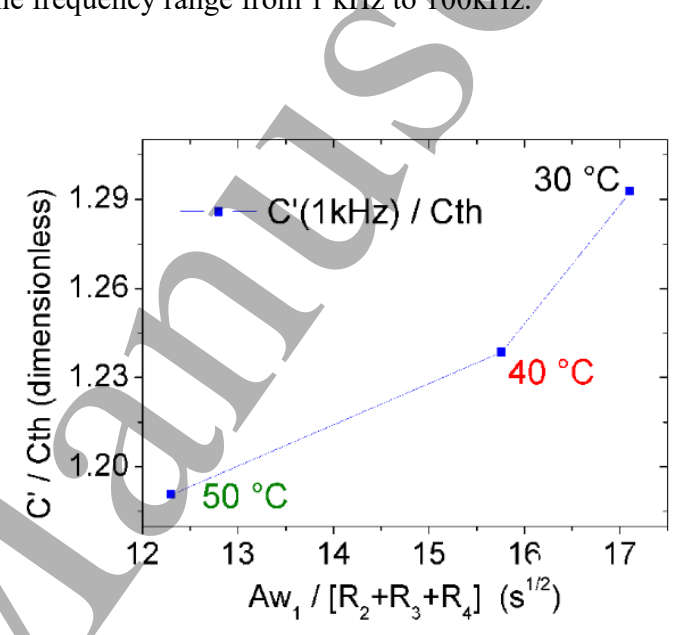

(b)

Figure 7. C' / $\mathrm{C}_{\mathrm{TH}}$ versus $\mathrm{Aw}_{1} /\left(\mathrm{R}_{2}+\mathrm{R}_{3}+\mathrm{R}_{4}\right)$ showing a reduction with the temperature increase: (a) capacitance is measured at $0.1 \mathrm{~Hz},(\mathrm{~b})$ capacitance is measured at $1 \mathrm{kHz}$.

Table 3. Impedance spectroscopy parameters for the modelled polystyrene nanoparticle MIM capacitor at three different temperature T $\left({ }^{\circ} \mathrm{C}\right)$.

\begin{tabular}{|c|c|c|c|c|c|c|c|c|c|c|c|c|}
\hline $\begin{array}{l}\mathbf{T} \\
{ }^{\circ} \mathbf{C} \\
\end{array}$ & $\begin{array}{l}\mathbf{Q}_{\mathrm{C} 1} \\
\mathrm{nFs}^{\alpha-1} \\
\end{array}$ & $\alpha_{1}$ & $\begin{array}{l}\mathbf{A}_{\mathrm{W} 1} \\
\mathrm{M} \Omega^{\mathrm{s} 1 / 2}\end{array}$ & $\begin{array}{l}\mathbf{Q C}_{\mathbf{C}} \\
\mathrm{nFs}^{\alpha-1} \\
\end{array}$ & $\begin{array}{l}\mathbf{R}_{2} \\
\mathrm{M} \Omega \\
\end{array}$ & $\begin{array}{l}\mathbf{Q C 3}_{\mathrm{C3}} \\
\mathrm{nFs}^{\alpha-1}\end{array}$ & $\boldsymbol{\alpha}_{3}$ & $\begin{array}{l}\mathbf{R}_{3} \\
\mathrm{M} \Omega \\
\end{array}$ & $\begin{array}{l}\mathbf{Q}_{\mathrm{C4}} \\
\mathrm{nFs}^{\alpha-1}\end{array}$ & $\alpha_{4}$ & $\begin{array}{l}\mathbf{R}_{4} \\
\mathrm{M} \Omega \\
\end{array}$ & $\begin{array}{l}\mathbf{C}_{\text {Resist }} \\
\mathrm{pF}\end{array}$ \\
\hline 30 & 1.60 & 0.97 & 410 & 0.94 & 22 & 1.3 & 1.0 & 1.8 & 1.9 & 1.0 & 0.16 & 33 \\
\hline 40 & 1.60 & 0.97 & 430 & 0.94 & 25 & 1.3 & 1.0 & 2.0 & 1.8 & 1.0 & 0.29 & 33 \\
\hline 50 & 1.40 & 0.97 & 500 & 0.96 & 35 & 1.1 & 1.0 & 5.0 & 1.8 & 1.0 & 0.65 & 33 \\
\hline
\end{tabular}

Finally, we consider that dipolar polarization effect is negligible with the temperature variation, due to the nonpolar nature of the polystyrene molecules and because phenylgroups are immobilized at temperatures below glass transition temperature either for polystyrene film $\left(97^{\circ} \mathrm{C}\right.$ to $\left.107^{\circ} \mathrm{C}\right)$ or for PS nanoparticles $\left(67.8^{\circ} \mathrm{C}\right)$ [30].

\section{Conclusions}

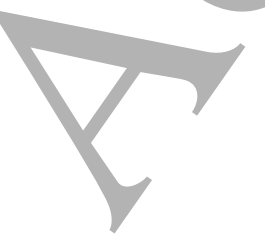

A novel polystyrene (PS) MIM capacitor was fabricated using $295 \mathrm{~nm}$ PS nanoparticles as insulator layer. Electrospray technique was used to deposit a $1.75 \mu \mathrm{m}$ average thickness of nanoparticles film on an area of $20.25 \mathrm{~mm}^{2}$. This device offered a higher capacitance (up to 11.7) and loss tangent (up to 387) values than the expected for an equivalent same dimensions MIM capacitor with a continuous PS film. This high capacitance is attributed in part to space charges localized at the nanoparticles interface. 
Impedance spectroscopy was studied and modelled by a modified randles circuit consisting of four sub-circuits. The Nyquist plot revealed a straight line without effective relaxation points indicating a good capacitive behaviour.

The temperature study revealed a slight decrease in the capacitance in the whole frequency range as the temperature increase. Furthermore, an increment of the shunt resistances and the Warburg coefficient indicates that the deterioration of the metal contacts and the reduction of charge diffusion due to evaporation, are the main two facts that contributes to the reduction of the capacitance.

Given the higher presence of charges in the PS nanoparticles MIM capacitor than in a conventional film MIM capacitor, and the simplicity of the electrospray technique, we hope that this work will open up new possibilities for their application. The potential of this device can be explored using different type of dielectric material as insulator layer. In addition, the functionalization of the nanoparticles and the use of electrolytes electrochemically compatible with the surface of the nanoparticles can improve the overall performance of the device.

\section{Acknowledgements}

This work has been supported by the Spanish Ministry of Science and Innovation under projects TEC2014-59736-R, ESP2016-79612-C3-2-R. The activity was carried out under a programme of, and funded by the European Space Agency under project ESA AO/1-8876/17/NL/CRS. This work was also supported by SENESCYT of the republic of Ecuador. The authors thank Triffon Triffonov by the measurement performed at UPC CRNE.

\section{References}

[1] Mu J, Chou X, Ma Z, He J and Xiong J 2018 Highperformance MIM capacitors for a secondary power supply [20] application Micromachines 9 1-10

[2] Han F, Meng G, Zhou F, Song L, Li X, Hu X, Zhu X, Wu B and Wei B 2015 Dielectric capacitors with threedimensional nanoscale interdigital electrodes for energy storage $S c i$. Adv. 1 1-7

[3] Banerjee P, Perez I, Henn-Lecordier L, Lee S B and Rubloff G W 2009 Nanotubular metal-insulator-metal capacitor arrays for energy storage Nat. Nanotechnol. 4 292-6

[4] Wei L, Liu Q, Zhu B, Liu W, Ding S, Lu H, Jiang A and Zhang D W 2016 Low-Cost and High-Productivity ThreeDimensional Nanocapacitors Based on Stand-Up ZnO Nanowires for Energy Storage Nanoscale Res. Lett.

[5] Li L, Zhu B, Ding S, Lu H, Sun Q, Jiang A and Zhang D W 2012 Three-dimensional AlZnO / Al 2 O 3 / AlZnO nanocapacitor arrays on Si substrate for energy storage Nanoscale Res. Lett. 71

[6] Coll A, Bermejo S and Castañer L 2014 Self-assembly of ordered silica nanostructures by electrospray Microelectron. Eng. 121 68-71

[7] Véliz B, Bermejo S, Orpella A and Castañer L 2018 Impedance modeling of silica nanoparticle metal insulator metal capacitors Electrochim. Acta 280 62-70

[8] Huan T D, Boggs S, Teyssedre G, Laurent C, Cakmak M,
Kumar S and Ramprasad R 2016 Advanced polymeric dielectrics for high energy density applications Prog. Mater. Sci. 83 236-69

[9] Treich G M, Tefferi M, Nasreen S, MannodiKanakkithodi A, Li Z, Ramprasad R, Sotzing G A and Cao Y 2017 A rational co-design approach to the creation of new dielectric polymers with high energy density IEEE Trans. Dielectr. Electr. Insul. 24 732-43

[10] Hardy C G, Islam M S, Gonzalez-Delozier D, Morgan J E, Cash B, Benicewicz B C, Ploehn H J and Tang C 2013 Converting an electrical insulator into a dielectric capacitor: End-capping polystyrene with oligoaniline, Chem. Mater. 25 799-807

[11] Mark J E 1999 Polymer Data Handbook ed J E Mark (Oxford University Press)

[12] Coll A, Bermejo S, Hernández D and Castañer L 2013 Colloidal crystals by electrospraying polystyrene nanofluids Nanoscale Res. Lett. 8

[13] John D. Joannopoulos, Steven G. Johnson, Joshua N. Winn R D M 2008 Photonic Crystals Molding the Flow of Light (New Jersey: Princeton University Press)

[14] Colvin V L 2001 From Opals to Optics: Colloidal Photonic Crystals MRS Bull. 26 637-41

[15] Coll A, Bermejo S, Hérnández D and Castañer L 2018 $\mathrm{Al} 2 \mathrm{O} 3 / \mathrm{TiO} 2$ inverse opals from electrosprayed selfassembled templates Beilstein J. Nanotechnol. 9 216-23 [16] Bibi F, Villain M, Guillaume C, Sorli B and Gontard N 2016 A Review: Origins of the Dielectric Properties of Proteins and Potential Development as Bio-Sensors Sensors 161232

Ahmad Z 2012 Polymer Dielectric Materials Dielectric Material ed M A Silaghi (Rijeka: InTech) Y.K.Kulshrestha; A.P. Srivastava; 1980 Dielectric properties of polystyrene and polystyrene-chloranil Thin Solid Flilms 71 41-5

[19] McCammon R D, Saba R G and Work R N 1969 Dielectric properties of polystyrene and some polychlorostyrenes from $4^{\circ} \mathrm{K}$ to room temperature $J$. Polym. Sci. Part A-2 Polym. Phys. 7 1721-33 Baer E and Zhu L 2017 50th Anniversary Perspective: Dielectric Phenomena in Polymers and Multilayered Dielectric Films Macromolecules 50 2239-56

[21] S. Wilm, Matthias; Mann M 1994 Electrospray and taylor cone theory dole's beam of macromolecules at last Int. J. Mass Spectrom. Ion Process. 167-80

[22] Rieger J 1996 The glass transition temperature of polystyrene J. Therm. Anal. 46 965-72

[23] Jorcin J, Orazem M E, Nadine P and Tribollet B 2006 CPE analysis by local electrochemical impedance spectroscopy 51 1473-9

[24] E. Barsoukov J R M 2005 Impedance Spectroscopy: Theory, Experiment, and Applications (John Wiley \& Sons)

[25] Véliz B, Bermejo S, Coll A and Castañer L 2014 Metalinsulator-metal capacitor using electrosprayed nanoparticles Appl. Phys. Lett. 105

[26] Vassilikou-Dova A and Kalogeras I M 2008 Thermal Analysis of Polymers: Fundamentals and Applications (John Wiley \& Sons)

[27] P.K.C Pillai; and Rashmi 1980 Dielectric Properties of Polysrene and Some Related Polymers Int. J. Polym. Mater. Polym. Biomater. 255-63

[28] Electronics T 2007 Polystyrene Film \& Foil 118-23

[29] J Brad, Allen \& R Faulkner L 2000 Electrochemical

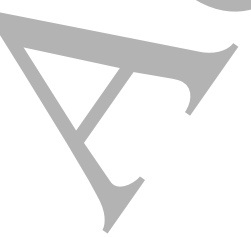


Methods: Fundamentals and Applications. (JOHN WILEY \& SONS INC)

[30] Davodi B, Lashkenari M S and Eisazadeh H 2011

Fabrication and thermal degradation behavior of

polystyrene nanoparticles coated with smooth polyaniline Synth. Met. 161 1207-10 